\title{
Acolhimento na Atenção Básica: reflexões éticas sobre a Atenção à Saúde dos usuários
}

\author{
User embracement in Basic Care: \\ ethical implications on the $\mathrm{H}$ ealth Care of the users
}

Laura Cavalcanti deFarias Brehmer ${ }^{1}$

Marta Verdi ${ }^{1}$

${ }^{1}$ UniversidadeFederal de SantaCatarina. Campus Universitário Trindade. 88010-970 Florianópolis SC lauracavalcanti@bol.com.br
Abstract This article identifies and analyses the ethical implications originated from the daily activities of user embracement in basic health units and its implications on the $\mathrm{H}$ ealth Care of the users of the Brazilian U nified Health System. It'sa qualitative study of exploitative descriptive design which took place in 5 basic health unit from city's health system of an important city in the state of Santa Catarina (Brazil); 26 individuals have been interviewed, among them are managers, health employees and users. Analyzed in the light of the references of the daily bioethics' and protection bioethics' approaches, theembracement in thecases studied revealed contexts filled with ethical conflicts which emerge from routine activities in health care, showing technical and conceptual distancing, as well as structural limitations. The user's statements pointed out outstanding differences between the users desire to feel embraced re spectfully and having their needs accomplished and the frustrating experiences they experienced in the basic health units' daily routine, which reveal situations of exclusion and denial on what concerns to the right to health. The results represent a setback in the implementation of this practice in accordance with the principles of universality in the access, integrality in careand the guarantee of the right to health.

Key words Primary Health, U ser embracement, Bioethics
Resumo 0 presenteartigo identifica eanalisa as implicações éticas oriundas das práticas cotidianas de acolhimento em U nidades Básicas deSaúde (UBS) e seus reflexos na Atenção à Saúde dos usuários do Sistema Ú nico de Saúde (SUS). Trata-se deum estudo qualitativo de design exploratório-descritivo realizado em cinco U BS da rede municipal de saúde de um município de grande porte do estado de Santa Catarina. Foram entrevistados 26 sujeitos, entre gestores, trabalhadores da saúde e usuários. Analisado à luz dos referenciais das abordagens da bioética cotidiana e da bioética da proteção, o acolhimento nas realidades pesquisadas revel ou contextos permeados por conflitoséticos queemergem do dia a dia das ações nos serviços de saúde. M ostrou ainda distanciamentos técnicos e conceituais, bem como limitações estruturais. $\mathrm{Na}$ voz dos usuários, sobressaíram diferenças marcantes entre 0 que se caracterizou como o desejo de se sentir acolhido com respeito, tendo atendidas suasnecessi dades, eas frustrantes experiências vivenciadas no cotidiano das UBS, as quais revelam situações de exclusão e negação do direito à saúde. 0 s resultados obtidos representam um revés na implementação desta prática em consonância com os princípios da universalidade no acesso, da integralidade na atenção e da garantia do direito à saúde. Palavras-chave Atenção Básica, Acolhimento, Bioética 
Introdução

Desde 1988, depois de quase duas décadas da promulgação da Constituição Federal Brasileira, o cenário das ações e práticas da Saúde Pública voltou-se para a construção de um novo modelo de assistência à saúde. N esse processo, são inúmeros os efforços para efetivar as prerrogativas do Sistema Ú nico de Saúde (SUS) e garantir, no campo real, seu funcionamento conforme sua base teórica e conquista legal. Este estudo tomou, inicialmente, por referência a Política $\mathrm{Nacional}$ de Humanização (PNH) elaborada em 2004 para atuar transversalmente em toda a rede do SU S. Seu marco teórico-político configura-se em torno da humanização das práticas de atenção e gestão como uma dimensão fundamental do sistema de saúde.

Essa política se propõe a fomentar princípios e modos de operar no conjunto das relações entre profissionais e usuários, entre os diferentes profissionais, entre as diversas unidades e serviços de saúde e entreas instâncias que constituem o SUS. Um dos dispositivos da políticaéo acolhimento, que compreende desde a recepção do usuário no sistema de saúde e a responsabilização integral de suas necessidades até a atenção resolutiva aos seus problemas ${ }^{1}$.

A PNH integra 0 acolhimento aos seus "modos de fazer". Esta prática, como estratégia, foi implementada desde as primeiras propostas de reorientação da atenção à saúde, constituindo-se numa diretriz do novo modelo tecnoassistencial. 0 acolhimento propõe reorganizar o serviço no sentido de oferecer sempre uma resposta positiva ao problema de saúde apresentado pelo usuário².

Pode-se compreender 0 acolhimento, simultaneamente, como uma diretriz euma estratégia. Segundo Takemoto e Silva ${ }^{3}$, essa prática nos serviços de saúde denota a reorganização do trabaIho ea postura diante da atenção às necessidades dos usuários. A articulação dessas perspectivas traduz as intenções de um atendimento com garantia do direito de acesso aos serviços e da humanização das relações estabeleci das no cotidiano das instituições.

Embora se entenda que 0 acolhimento deva perpassar todos os níveis da Atenção à Saúde, para atender ao escopo desta pesquisa a investigação foi circunscrita à Atenção Básica, ou seja, ao primeiro nível de atenção na organização da rede hierarquizada dos serviços do SUS.

Os estudos em torno dessa temática estão basicamente delineados na perspectiva estrutural e organizacional de uma atividade implanta- da com vistas às transformações propostas pelo SUS. Assim, são incipientes as pesquisas que retomam o acolhimento na perspectiva ética. Como dispositivo de uma política de humanização dos serviços de saúde, o acolhimento traduz a ação humana de reconhecer a dimensão subjetiva do ser humano, considerando-o como sujeito histórico, social e cultural. Portanto, essa estratégia pretendeultrapassar os limites técnico-operacionais de uma atividade programada e tanger as esferas dos valores éticos.

O programaÉtica do Acolhimento da Prefeitura Municipal de São Paulo, em parceria com a Associação Palas Athena ${ }^{4}$, em 2002, publicou um ensaio sobre a articulação intrínseca da ação do acolher com a dimensão ética dos sujeitos e dos serviços. N ele, os aspectos técnico-operacionais, predominantes nas instituições e nas ações dos profissionais, se sobrepõem à atitude humana de valor ético social, de responsabilidade e respeito. Esta sobreposição constitui o maior problema enfrentado no cotidiano dos serviços, de onde emerge a necessidade de discutir os conflitos que uma prática imbuída de consciência da subjetividade dos sujeitos pode gerar, para não transformá-la em mais uma técnica, dentre as demais atividades mecânicas e reducionistas.

A atitude deacolher pressupõe a mobilização dos sujeitos envolvidos em todos os aspectos das relações que se estabelecem no âmbito da saúde. É necessária uma consciência de cidadania. Devese reconhecer nas estratégias propostas pelo SUS um caminho para exercer o direito ao acesso universal e conquistar a integralidadee a equidadeda assistência à saúde. N esse contexto, o espaço do acolhimento na Atenção Básica à Saúde compõe um potencial cenário para conflitos éticos no dia a dia das ações.

0 objetivo do presente estudo foi analisar as implicações éticas no acolhimento, a partir da percepção dos atores envolvidos: gestores, trabalhadores da saúde e usuários, considerando a necessidade de refletir acerca da dimensão ética no processo de acolher os usuários nos serviços de saúde e de oferecer uma assistência integral e com qualidade, no cenário das UBS em uma rede municipal.

Para subsidiar a análise, a bioética cotidiana ea bioética da proteção constituíram um importante referencial devido a sua aplicabilidade teórica às situações-problemas provenientes dos serviços de saúde, sobretudo no âmbito da SaúdePública.

A bioética cotidiana, segundo Berlinguer ${ }^{5}$, surge da necessidade de resgatar a atenção para 
os comportamentos eideias de cada pessoa. Busca compreender, contextualizar e discutir as implicações da subjetividade humana no cotidiano dos serviços de saúde.

A bioética da proteção toma como referência o objetivo básico na Saúde Pública no contexto brasileiro, em que a saúdeéum dever do Estado e um direito detodo cidadão. Os conflitos éticos da Saúde Pública podem ser enfrentados, para Schramm e Kottow 6 , por meio de uma nova concepção da bioética, a "bioética da proteção".A ação protetora do Estado deve garantir o direito social do acesso aos serviços de saúde, com qualidade e respeito aos direitos humanos fundamentais.

\section{Percurso metodológico}

Trata-se de um estudo de abordagem qualitativa edesign exploratório-descritivo, realizado na rede básica de saúde de um município de grande porte do estado de Santa Catarina, onde está implantada a Política Nacional de Humanização.

Os sujeitos da pesquisa foram gestores, trabalhadores da saúde e usuários, sendo a amostra composta por 26 sujeitos, distribuídos em nove gestores, dez trabal hadores de saúde e sete usuários. Estes sujeitos foram escol hidos aleatoriamente, por acessibilidade e disponibilidade para participar, a partir de cinco Unidades Básicas de Saúde (UBS), uma de cada regional de saúde do município, eleitas por sorteio.

A coleta dos dados processou-se por meio de entrevistas, seguindo o padrão semiestruturado, com uso de roteiro sistematizado em duas partes: a primeira, duas situações-problemas; a segunda, perguntas abertas referentes à temática da pesquisa.

A etapa de análise dos dados seguiu a técnica de análise de conteúdo proposta por Bardin ${ }^{7}$, resultando na constituição de quatro categorias temáticas.

Para garantir os aspectos éticos de uma pesquisa envolvendo seres humanos, este estudo foi apreciado e aprovado pelo ComitêdeÉtica e Pesquisa com Seres Humanos (CEPSH) da Universidade Federal de Santa Catarina. Para garantir o anonimato dos sujeitos, foram adotados códigos para identificação das informações por meio do uso das iniciais de suas categorias de sujeitos: letra $\mathrm{G}$ para gestores, letra T para trabal hadores e letra U para usuários. Seguida à letra inicial de cada categoria, foi atribuída uma numeração em algarismo romano, conforme o total de sujeitos em cada categoria.

\section{Discussão}

Acolhimento:

incongruências entre discursos e práticas

A análise dos dados obtidos nas entrevistas com gestores e trabalhadores da saúde revelou contradições entre as percepções subjetivas e a descrição das experiências como atores do processo de acolhimento. Tais evidências foram dispostas em dois eixos de distanciamento: um com uma face de caráter conceitual, o outro referente às práticas reais de acolher.

A primeira incongruência observada expressa o distanciamento entre o discurso do acolhimento e os modos de acol her revelados na prática. Em uma face do discurso, o acolhimento é compreendido como método de escuta atenta e qualificada, e os modos de acolher, revelados na prática, se restringem a estratégias para 0 atendimento deurgências.

Gestores e trabalhadores expõem sua concepção sobreacolhimento econvergem parauma definição baseada fundamentalmente na relação estabelecida com os usuários. Acolher éouvir suas necessidades, de modo a oferecer respostas. Entretanto, é importante ressaltar que ao ato de ouvir éatribuído um caráter especial, pois envolve muito além do sentido de ouvir, tornando um ato mecânico uma ação humana sensível. É imprimir ao simples ato de ouvir a capacidade humana de escutar, de estar atento ao outro.

A essa escuta é atribuído o adjetivo "qualificada". Assim, a premissa da recepção de um usuário, segundo refletem os sujeitos, deve ser orientada pela escuta qualificada dos problemas demandados aos serviços. Saber ouvi-la principalmente... E dar resolutividade para o problema dela (T IV).

Diversos autores têm discutido a importância da escuta e aten ção às necessidades dos usuários; dentre eles destacam-se Franco et al. ${ }^{8}$, que apontam 0 acolhimento como a diretriz operacional fundamental para a inversão do modelo tecnoassistencial no SUS. Tal diretriz sustenta-se em pilares como a garantia da acessibilidade universal ea qualificação das relações, na qual escuta e atenção às necessidades são fundamentais ao processo para que o serviço ofereça uma resposta sempre positiva aos problemas apresentados pelos usuários.

Teixeira ${ }^{9}$ propõe a discussão do "acolhimento dialogado" como técnica de conversa, com características peculiares e norteadas por princípios éticos, passível de ser realizada por qualquer 
profissional em qualquer momento do atendimento. A proposta éconceber a ação na perspectiva mais humana, evitando sua interpretação exclusivamente tecnicista, e valorizar todas as demandas individuais.

Entretanto, os discursos dos sujeitos na pesquisa mostraram-se divergentes nos relatos dos modos de acolher operados na prática dos serviços. Os discursos são encobertos por descrições de atendimentos pontuais, e 0 acolhimento, na prática, setorna sinônimo de atendimento de urgência. Trata-se, neste caso, da atenção dada às pessoas que diariamente recorrem às unidades de saúde com umanecessidadeimediata e, pela limitação do acesso, não conseguem atendimento agendado. Elas, então, são acolhidas, desde quesua demanda seja aval iada como importanteefactível. N um caso de dor, a gente vai perguntar o que ele precisa. Um caso de urgência, isso éacolhimento (T III).

Percebe-se que a preocupação com a qualidade da escuta, presente nos discursos, distancia-se substancialmente dos modos como os sujeitos descrevem a organização do acolhimento no cotidiano dos serviços de saúde.

0 conjunto articulado de princípios que orientam a Aten ção Básica, a Estratégia de Saúde da Família (ESF) e a PNH parece ser esquecido, ou mesmo abandonado, no processo de organização dos serviços e execução das ações, revelando, assim, a fragilidade ea inconsistência na construção das ações. Cabe considerar a construção do processo, arraigada à superação de limites organizacionais e paradigmáticos. Contudo, a gestão dos serviços mostra-se, de certa forma, atrelada a esses limites. Os trabal hadores, à margem da gestão, al gumas vezes parecem impotentes diantedos obstáculos concretos e não sinalizam para algum movimento de reação, pois são absorvidos pela rotina sem perceber; em outras parecem conscientes, porém apáticos à própria condição.

0 segundo eixo de distanciamento corresponde ao paradoxo entre o discurso do direito ao acesso universal à saúde e a estratégia de organização da demanda espontânea.

Ao acolhimento, éatribuído também o significado de acesso aos serviços de saúde. É uma das ações estratégicas para contemplar um direito à saúde garantido no artigo 196 da Constituição Federal Brasileira de 1988.

Considerada a porta de entrada prioritária para o usuário no sistema de saúde, a Atenção Básica exerceo papel degrande acolhedora edeve, como todos os outros serviços, atender a todos. Quando impossibilitada de oferecer respostas, por questões de organização ou competência, a
Atenção Básica deverá dispor de uma rede de re ferências de serviços e canais de fluxos que permitam encaminhamentos.

A Portaria M Sn ${ }^{\circ} 648 / 2006$, que trata da Política Nacional de Atenção Básica, em seu capítulo 1 , determina, dentre diferentes princípios, 0 acesso universal e contínuo, bem como a efetivação da integralidade das ações programáticas e demanda espontânea ${ }^{10}$.

De posse das concepções teóricas e determinações legais, bem como dos relatos dos sujeitos acerca da estruturação da assistência nas U BS, é possível identificar questões sobre a ineficiência da programação das unidades ante os problemas reais das comunidades, seguindo a lógica verticalizada das suas ações.

0 acolhimento surgiu como uma atividade programada para a atenção da demanda espontânea. A ação mecânica reduz um processo com diferentes e complexas interfaces a simplesmente mais uma atividade da unidade para 0 atendimento daqueles que não foram, por critérios de classificação e seleção, elencados para a atenção. É perguntar o que a pessoa está sentindo ou o que ela está precisando no momento enão só dizer não tem, "tchau" ( T III).

Há nitidamente uma distinção técnica entre acolhimento, como atividade de atendimento para demanda espontânea, e atenção humanizada às necessidades dos usuários como preconiza a PNH. Acolher restringe-se a uma situação focada em um problema, preservando no cotidiano das unidades 0 acesso limitado e a atenção centrada na queixa-conduta.

Essas situações podem ser analisadas na ótica da bioética da proteção, da premente questão do papel do Estado na garantia do acesso aos serviços públicos de saúde. Diante do valor da saúde como bem de cidadania, Schramm ${ }^{11}$ desenvolveu o conceito de proteção aplicado à Saúde Pública a partir da integração entre a responsabilidade moral e a pragmática. Estas seriam aplicadas às políticas sanitárias universais, a exemplo do SUS. Neste contexto, cabeao gestor a responsabilidade instituída para a garantia das ações correspondentes às necessidades de saúde da população, protegendo-a de ameaças concretas.

A implicação identificada justifica-se na observação de um cenário avesso ao apregoado pelos direitos legais de acesso à saúde garantido mediante as políticas públicas de responsabilidade do Estado.

A apropriação desse referencial e sua aplicação na análise dos conflitos oriundos da negação da responsabilidade sanitária do Estado permi- 
tem a constante avaliação do desempenho e da implementação das políticas públicas. É através desta avaliação que se estabel ece um olhar crítico e reflexivo acerca da qualidade delas, ainda que se constatem numerosas contradições no seu exercício prático.

Num contexto desigual, em que o Estado mínimo trava uma disputa diária com o social, 0 direito à saúde faz-se imperativo nos discursose nas ações dos agentes institucional mente constituídos, gestores e trabal hadores da área. 0 acesso significa o início do processo de resgate da cidadania e da responsabilidadeindividual; o não reconhecimento do direito distancia os sujeitos do seu papel de agente participativo na construção da cidadania.

Acolher com limitações: a organização da oferta e a oferta desordenada

N esta categoria, são discutidas al gumas questões emergentes dos relatos de gestores e trabaIhadores quanto às condições da estrutura organizativa dos serviços básicos de saúde. Também emergiram desses discursos as influências da evolução do modelo assistencial que representam obstáculos para a prática do acolhimento. Foram identificados limites estruturais, de esfera técnica, e limites conceituais, de esfera doutrinária.

As limitações técnicas correspondem às precariedades das estruturas físicas das unidades de saúde e à escassez de profissionais. São estruturas insuficientes para responder adequadamente à demanda requerida pelos usuários. As restrições correspondem essencialmente à exiguidade de espaço físico eà divisão da área que, por vezes, resulta em espaços inadequados.

No âmbito dos recursos humanos, outro limite apontado foi a falta de profissionais nas equipes de saúde. A demanda é expressiva, porém a organização da oferta com profissionais suficientes ainda está aquém do desejável para um atendimento de real efeito para usuários. 0 fato reflete negativamente também para os trabalhadores, pois a exaustão, o cansaço e a incapacidade de atender a todos os usuários e cumprir com todas as exigências do Sistema tornam o profissional insatisfeito. Pensar unilateralmente na satisfação dos usuários é efêmero; quem está no exercício de sua profissão carece de respaldo para sua boa atuação. Falta de funcionári0S: se cada um tivesse com seu setor preenchido, ele teria mais tempo para fazer acolhimento ( $\mathrm{T}$ III).

A PNH orienta as suas estratégias também para os trabalhadores, na valorização da sua di- mensão subjetiva, na qualidade da ambiência e no fomento da educação permanente.

Do ponto de vista estrutural, foi possível identificar duas questões éticas oriundas das deficiências físicas das unidades de saúde e relatadas como conflitos cotidianos enfrentados pel os usuários: 0 direito à privacidade e ao sigilo.

Sacardo eFortes ${ }^{12}$ definem privacidade como o consenso que existe em um mecanismo de regulação entre sujeitos no estabelecimento de sua relação e mediado pela confiança.

Zoboli13, em seu estudo acerca de questões éticas implicadas numa experiência de Atenção Básica à Saúde, observou a inegável influência da estrutura física na exposição dos usuários. As arquiteturas insustentáveis são geratrizes de situações éticas conflituosas e dificultam o desenvolvimento deuma relação de confiança evínculo entre trabalhadores e usuários. U m local adequado, se nós formos ol har a realidade das unidades, nem todas possuem um espaço onde a pessoa possa, sem ser no balcão onde todas as outras estão ouvindo, colocar a gravidade do seu estado, a urgência do seu atendimento, sem se expor (G IV).

$O$ acolhimento é reprimido pela ausência de condições básicas de receber os usuários respeitando o seu bem privado, suas necessidades particulares, dedomínio individual. A configuração física e o modo como são distribuídos os espaços nas unidades de saúde propiciam a exposição e constituem um entrave para acolher.

Inerenteà questão da privacidade, insere-sea confidencialidade das informações. A correlação existe no momento em que o âmbito privado passa a ser de conhecimento de outrem e exige deste a postura de não revelar qualquer informação sem a autorização da pessoa que confiou nele. 0 que é observado é que as condições adversas de trabalho podem velar a violação de princípios, em detrimento do atendimento das demandas.

Nesse momento, a análise ultrapassa a fronteira técnica eatinge um plano para além da avaliação factual. 0 processo histórico, o conjunto complexo de todos os fatos que determinam socialmente o saber e o fazer, é o cenário principal. e é em consonância com ele que se inserem as estruturas e os atores.

$\mathrm{Na}$ história das políticas públicas de saúde no Brasil, o atual sistema é considerado revolucionário, visto em seus princípios e diretrizes, sobretudo pela proposta transformadora das práticas hegemônicas.

$M$ endes ${ }^{14}$ enumera três dimensões representativas da complexidade do sistema social em 
construção e que são referências para voltar os olhares da reflexão: a dimensão política, a dimensão ideológica e a dimensão tecnológica. Destaca-se a dimensão ideológica, visto que os atores sociais desta pesquisa, copartícipes e corresponsáveis pelo processo, revelaram perspectivas limitadas quanto ao paradigma sanitário e contradições entre dois model os em um mesmo contexto, em que sobressaem as impressões do modelo biomédico.

Os entraves ideológicos são subjetivos, com influências dos determinantes sociais em contextos propícios. A transformação começa em cada sujeito, nas concepções e nas ações, porém as adversidades estruturais contribuem para tolher manifestações nesse sentido. A gente criou uma população que acredita que precisa ser medicalizada, que precisa ter um aparato de exames para resolver uma dor de cabeça (G VI).

Constataram-se descrições, segundo as experiências, deum perfil comum deusuários, pessoas com necessidades, via de regra, de atenção curativa, na qual há o reconhecimento de que este perfil é produto da historicidade social das concepções do processo saúde-doença.

Do reducionismo teórico, conformado pelo processo histórico, emerge outra implicação ética. Trata-se do desrespeito à autonomia do sujeito e que se configura em dois planos: o micro, pela ação de gestores e trabalhadores de saúde, $e$ o macro, modulado pelo paradigma biomédico. Resulta desta interação uma atenção que desqual ifica o usuário como protagonista da sua saúde e o personifica apenas com características fisiopatológicas. Por conseguinte, esses sujeitos destituídos de suas características subjetivas, diante da heteronomia profissional, reproduzem papéis a eles atribuídos. Esses sujeitos são privados do pensamento e da prática individual autônoma; não são respeitados, portanto, os preceitos requeridos para uma relação com essa base interativa.

A autonomia de gestores e trabalhadores da saúde, conforme recomenda a PNH, segundo seus próprios depoimentos, parece ser também desrespeitada pelo efeito magno do modelo clínico. Tal fato mostra-se impresso na inércia desses protagonistas ante as demandas; assim sendo, o acolhimento se torna uma opção para responder pontualmente às necessidades de atenção médica, curativa e de medicalização.

Berlinguer ${ }^{15}$ refletea influência da biomedicina sobre a face desumana da Atenção à Saúde. 0 autor considera os avanços advindos das práticas especializadas, mas chama a aten ção para que o apelo por atitudes humanizadas não seja pro- pagado com resistência al heia à qualificação, ainda que técnica, dos tratamentos às doenças. Um processo não deve ocorrer em detrimento do outro; trata-se de percorrer um caminho fronteiriço entre as faces do atendimento técnico e humano.

0 acolher, como estratégia de humanização nos serviços, pode estar ameaçado pela tendência de tecnificação. Assim, ele trafega pelo tênue limiar da reprodução de modos e da reformulação de posturas.

Numa crítica ao reducionismo da biomedicina, Soares eC amargo J unior ${ }^{16}$ propõem um conceito complexo para a autonomia, baseado na interdependência entre os sujeitos e seus meios, nas relações democráticas de saberes, respeito, responsabilidade e valorização da subjetividade. Quando aplicado ao contexto das instituições públicas de saúde, a reflexão perpassa a desigualdade resultante da relação de poder esaber, estabelecida entre gestores e trabal hadores e usuários como o principal obstáculo ao respeito da autonomia.

0 acolhimento, orientado por princípios e posturas éticas, torna-se um campo fértil para a formação de sujeitos concretamente autônomos, protege a saúde individual e coletiva, bem como legitima uma política social neste âmbito.

\section{Acolhimento e atenção integral:}

aproximações e distanciamentos

Analisadas as percepções acerca do sentido da atenção integral para gestores e trabalhadores da saúde, foi possível identificar como esses atores reconhecem as necessi dades dos usuários ante os serviços e, especificamente, no processo de acolhimento. Desse reconhecimento emergiram três temas, explorados em seguida: o todo do serviço, o todo do sujeito e a fragmentação dos serviços; este último perpassa o produto da concepção e corresponde à relação concreta entre 0 acolher e $a$ atenção dispensada.

0 adjetivo integral qualifica a Atenção à Saúde nas bases legais das políticas públicas de saúde. 0 termo é empregado nos princípios doutrinários com o intento de caracterizar a garantia do acesso nos três níveis hierárquicos de Atenção à Saúde complexidade básica, média ealta - bem como as ações de promoção à saúde, prevenção de doenças e acidentes e reabilitação que compõem um conjunto articulado econtínuo deserviços sem prejuízos para nenhuma das assistênciaș ${ }^{1,17}$.

Pinheiro ${ }^{18}$ define a integralidade como uma ação social resultante da interação de atores na 
relação da demanda e da oferta, em um plano sistêmico, referente à rede de serviços, e um plano individual, construído na concretude da assistência, considerando os aspectos objetivos e subjetivos.

"O todo do serviço" corresponde ao plano sistêmico. Gestores e trabal hadores compreendem como atenção integral toda ação com vistas a oferecer todos os serviços de saúde cabíveis às necessidades dos usuários. A tendimento integral eu acho queénão só o paciente trazer um filho que está com dor de cabeça, aí pegou um paracetamol e foi embora. Eu acho que tem quever sea caderneta está completa, se ele está consultando, se ele está fazendo 0 acompanhamento direitinho, se ele foi no dentista (G III).

Faz-se uma breve pausa para destacar, a partir do depoimento citado, um exercício de domínio persecutório traduzido do entendimento desses gestores e trabal hadores sobre 0 atendimento integral. Observa-se uma postura controladora acerca de questões compreendidas como fundamentais na atenção completa ao usuário, mas que concretamente não garantem a ele condição digna de saúde.

Segue-se estabelecendo um parâmetro para um atendimento integral, segundo os trabalhadores da saúde, com base no acesso a todos os níveis de atenção dos serviços. Integral étudo que está precisando no momento. Se vai precisar de uma consulta médica, se vai precisar de um medicamento. Se chegar especialidade, ele precisa ser atendido pela especialidade (T II).

Como diretriz do SUS, integralidade, segundo M attos ${ }^{19}$, é parte de uma "imagem objetivo". Corresponde a uma meta, pouco específica, de onde parte a configuração da organização dos serviços a fim de atingir objetivos bem delineados como a construção de um novo modelo assistencial.

Parafraseando Pinheiro ${ }^{18}$, o conceito de integralidade toma, nesse momento, na compreensão dos sujeitos, o plano individual. "O todo do sujeito" refere-seà atenção considerando as múlti plas dimensões do sujeito, dentre as quais destacam-se a sua história, o seu contexto social e cultural. Atenção integral à saúde seria ver o paciente como um ser social dentro do seu meio social, familiar, psicológico e físico (G II).

Tais dimensões, junto com outras ainda surgidas, como a psicológica e a de valores próprios de cada individuo, foram todas resgatadas como determinantes do processo saúde-doença e da qualidade da atenção.

Ayres $^{20}$ corrobora os usuais conceitos de sujeito, amplamente empregados nos pensamen- tos sanitários. Para o autor, sujeitos são "seres autênticos, com suas necessidades e valores, capazes de produzir coisas e transformar sua própria história". Ele avança conceitualmente quando defendea tese da intersubjetividade, "o caráter imediatamente relacional e irremediavelmente contingente de nossas identidades e historicidades como indivíduos e grupos" 20 . A recognição é uma ação de dois ou mais sujeitos, portanto, denota olhar o outro como a si próprio.

"A fragmentação dos serviços" corresponde à expressão de gestores e trabal hadores sobre as reais limitações do atendimento integral às necessidades dos usuários. Não adianta a pessoa chegar na U nidadeBásica deSaúdee[...] por exemplo: o queeu resolvi do básico eu resolvi eo queéde média complexidadeealta complexidadenão acontece (G V).

Novamente, os determinantes estruturais constituem um significativo impedimento aos anseios de uma atenção voltada ao todo do serviço, como garantia de acesso, bem como consideração pela qualidade nos atendimentos, com resolutividade evoltada para todas as necessidades.

Do desejo de se sentir acolhido às experiências excludentes

Nesta categoria, buscou-se privilegiar a discussão das vozes uníssonas dos usuários, as quais evidenciaram, de um lado, mais que a percepção do melhor modo de acolher, o próprio desejo de se sentir acolhido; e de outro, as experiências vivenciadas no cotidiano das UBS, as quais se configuram em relatos denunciativos de exclusão e de negação do direito à saúde.

Inicia-se com a faceta positiva, para caracterizar o modo como os usuários expressaram o significado de se sentir acolhido - cabendo, nesse momento, registrar o desconhecimento desses sujeitos sobre o desenvolvimento deuma prática de acolhimento nas U BS. Diante desse fato, buscou-se resgatar a percepção dos usuários ante as suas expectativas em relação a como gostariam de ser acolhidos ou atendidos, o que pode ser evidenciado no relato a seguir: A cho queéal guém para chegar e perguntar o que você precisa, o que você quer dentro da sua necessidade. Informar se tem aqui ou se não tem aqui, porque tudo a gente tem que perguntar (U IV).

0 atendimento desejado se constitui de elementos como atenção e reconhecimento, permeando, sobre ambos, os direitos individuais e sociais. Refletir sobre o significado de se sentir acolhido pelos serviços de saúde proporcionou 
aos usuários expressar dois sentimentos: o primeiro, de caráter pontual, pois os usuários buscam soluções para suas necessidades; o segundo, de caráter subjetivo, uma vez que a atenção dispensada ao usuário deve ser derespeito. Estefato reforça as ideias anteriormente abordadas quanto ao acolhimento como ação que traduz atitudes dos sujeitos envolvidos. Significa, para os usuários, a postura de quem acolhe voltada para a qual idade da atenção expressamenter efletida pelo respeito ao ser humano, às suas demandas e sua fragilidade.

Apesar de a procura estar baseada em uma necessidade factível nos serviços, há um cenário de comportamento ético que perpassa todos os momentos da aten ção à saú de, e o susuários também o reconhecem como legítimo, para caracte rizar o seu acolhimento como ideal. São compromissos com a atenção da subjetividade, mas principalmente com o direito à saúde como fundamental a todos os seres humanos e garantido a todos os cidadãos.

Nesta perspectiva, os direitos do indivíduo, também chamados de direitos de primeira geração, podem ser definidos como os direitos subjetivos; correspondem à liberdade privada, são próprios da condição humana. Os direitos sociais ou de segunda geração referem-se à garantia para o pleno exercício público do indivíduo ${ }^{21}$. 0 direito à saúde figura em um desses direitos.

A faceta negativa do atendimento cotidiano nas U BS refere-se à privação do direito à saúde, garantido no plano legal. Os depoimentos a se guir em nada se assemelham aos anteriores, pelo conteúdo díspar em descrever o quanto sentem a negação do direito à saúde, sobretudo pelo limite de acesso aos serviços. É chegar 5 horas da manhã e perguntar o número de fichas e ouvir: "Ah, hoje só temos oito fichas." [...] Por que tem que ser no meio da semana para marcar a consulta? Quer dizer que o cidadão vai ter que esperar, vai ter dia para ficar doente? (U I).

São situações que expressam a negligência do direito à saúde, proposto em conformidade com valores éticos e legais. Uma geração de direitos jamais se sobrepõe à outra. N este caso, há uma violação dos direitos humanos e de cidadania, visto queo sujeito écolocado numa posição deprivação da liberdade individual e lhe é negado 0 acesso a um serviço garantido pela proteção do Estado.

Os usuários expressam sua decepção e a sensação de indignidade e impotência ante as suas vivências, de certa forma acentuadas pela condição de vulnerabilidade que a necessidade lhes confere. Eu venho só em último caso; por exemplo, agora estou com garganta inflamada, não tenho condições nem de comer. Esse é o último recurso que tenho (U I).

Esses relatos expressam o desrespeito à dignidadee novamente o descumprimento do papel do Estado. 0 acolhimento não existe no conhecimento prático, tampouco na interpretação do atendimento prestado. Os usuários se sentem completamente desprotegidos. A ética da proteção aplicada à saúde pública, na proposta de Kottow ${ }^{22}$, reforça a responsabilidade do Estado, definido como figura moral da proteção aos suscetíveis. Num contexto em que as desigualdades são persistentes eo desinter esse pelo bem comum predomina, surge um discurso bioético para 0 enfrentamento dos dilemas práticos oriundo de uma sociedade com essas características.

\section{Consideraçõesfinais}

A prática do acolhimento em todos os serviços públicos de saúdeorganiza-seem modos de atendimento aos usuários com a finalidade de garantir acesso e qualidade na atenção. Aliado às outras estratégias operacionais, 0 acolhimento visa, sobretudo, contribuir para a construção de um SUS universal e integral, como orientam seus princípios.

Contudo, o desenvolvimento desse processo no cotidiano das instituições de saúde pode revelar contradições edistanciamentos entreas intenções de uma prática e sua real aplicação nas situações concretas diárias. Este fato, certamente, representará um obstáculo para o pleno estabel ecimento das políticas públicas de saúde, bem como para a efetivação do SUS, em constantebusca pelo aperfeiçoamento de sua implantação no campo real das ações e dos serviços, sobretudo uma ameaça aos direitos conquistados social mente.

Retomando os objetivos deste estudo, o cotidiano das U nidades Básicas de Saúderevelou, nas percepções de seus protagonistas, um acolhimento aos usuários fundamentado, basicamente, em uma estratégia técnica de recepção, triagem eencaminhamento. Contrapondo-se a este perfil, configura-se num discurso consoante com os princípios da PNH um acolhimento ideal. Gestores e trabalhadores compreendem o processo de acolher como uma premissa do novo modelo de atenção à saúde.

O acolhimento apresenta-se com duas faces opostas edestoantes: no discurso, o reconhecimento do direito à saúde, e na prática, o descumprimento desta garantia constitucional. Estas situa- 
ções configuram o cotidiano das U BS e são pouco questionadas e discutidas, bem como o papel do Estado diante da garantia deste direito, fato que torna naturais a desigualdade e a exclusão.

As ações diárias nos serviços das U BS enfrentam alguns limites, dificultando a implementação do acol himento segundo sua orientação conceitual e técnica. Estes são classificados, principalmente, como limites de ordem estrutural e organizacional, porém são consideravelmente expressivas as limitações de ordem ideológica.

Analisada a atenção voltada às necessidades dos usuários, percebeu-seuma compreensão harmônica com os diversos conceitos de integralidade. Esta é percebida como a atenção às múltiplas dimensões dos sujeitos e como a totalidade na oferta dos serviços de saúde. Porém, a realidade revela uma fragmentação dos sujeitos e dos serviços pelas limitações dos serviços e por uma dificuldade subjetiva em não só compreender o outro como um todo, mas em respeitar esse todo.

Um importante retrato possível de ser construído com as informações dos usuários mostrou duas imagens díspares: entre a expectativa deum acolhimento ideal ea experiência frustrante da falta de acesso e da precariedade do atendi- mento que resulta em experiências excludentes.

Muito além deuma diferença teórica, 0 acolhimento, como prática, mantém-se atrelado a uma atividade técnica e à postura de acolher distante do ideal no plano real das ações. Uma estratégia que se propõe a ultrapassar as fronteiras técnicas e se fundamenta em princípios éticos e sociais é implementada com inúmeros reveses, atribuídos, principalmente, a determinantes organizacionais, porém com implicações éticas expressivas, como o descaso com a qualidade da atenção, a limitação do acesso e a negação do direito.

A reflexão ética das situações-problemas do cotidiano dos serviços básicos de saúde torna-se essencial para superar os limites, reavaliar as atitudes e efetivamente construir uma nova prática na atenção à saúde. Torna-se, em igual teor, um incentivo ao questionamento quanto ao papel assumido pelo Estado na proteção da saúde dos cidadãos.

No bojo desta discussão, está o respeito ao direito que os usuários possuem de terem sua saúde resguardada e suas necessidades atendidas. Anseia-se pelo fortalecimento desses sujeitos de direitos e pela compreensão da sua totalidade como seres humanos.

\section{Colaboradores}

LCF Brehmer e M Verdi participaram igualmente de todas as etapas da elaboração do artigo. 


\section{Referências}

1. Passos E, organizador. Formação de apoiadores para a política nacional de humanização da gestão e da atenção à saúde. v. 2. Rio de Janeiro: Editora Fiocruz; 2006.

2. Brasil. Ministério da Saúde. Política Nacional de Humanização - HumanizaSUS. Documento Base. Brasília; 2006. [site da Internet]. [acessado $2006 \mathrm{abr}$ 26] Disponível em: http://portal.saude.gov.br/ portal/arquivos/pdf/DB PNH.pdf

3. Takemoto M LS, Silva EM. Acolhimento e transformação no processo de trabalho de enfermagem em unidades básicas de saúde de Campinas, São PauIo, Brasil. Cad Saude Publica 2007; 23(2):331-340.

4. Associação Palas Athena. Ética do acolhimento. Revista THOT 2002; 77:63-69.

5. Berlinguer G. Questões de vida: ética, ciência e saúde São Paulo: Hucitec; 1993.

6. Schramm FR, Kottow M. Principios bioéticos em salud pública: limitaciones e propuestas. Cad Saude Publica 2001; 17(4):949-956.

7. Bardin L. Análise de conteúdo. Lisboa: Edições 70; 1977.

8. Franco TB, Bueno WS, Merhy EE. O Acolhimento e os processos de trabalho em saúde: o caso de Betim (M G). In: M erhy EE, Magalhães Júnior EM, Rimoli J, Franco TB, Bueno WS, organizadores. 0 trabalho em saúde: olhando e experienciando o SUS no cotidiano. 2a ed. São Paulo: Hucitec; 2004. p. 37-54.

9. Teixeira RR. Humanização e Atenção Primária à Saúde. Cien Saude Colet 2005; 10(3):585-597.

10. Brasil. M inistério da Saúde. Portaria no 648, de 28 de março de 2006. Brasília: Ministério da Saúde; 2006. [site da Internet]. [acessado 2006 abr 26]. Disponível em: http://dtr2004.saude.gov.br/dab/legislacao/ portaria_648_28_03_2006.pdf

11. Schramm FR. A bioética da proteção em Saúde Pública. In: Fortes PAC, Zoboli ELCP, organizadores. Bioética e Saúde Pública. São Paulo: Centro Universitário São Camilo/Edições Loyola; 2003. p. 71-84.

12. Sacardo DP, Fortes PAC. Desafios para a preservação da privacidade no contexto da Saúde Pública. [periódico na Internet] 2000 [acessado 2006 nov 16]. Disponível em: http://www.portalmedico.org.br Irevistalbio2v8/seccao2.htm l

13. Zoboli ELCZ. Bioética e Atenção Básica: um estudo de ética descritiva com enfermeiros e médicos do Programa de Saúde da Família [tese]. São Paulo: Universidade de São Paulo; 2003.

14. Mendes EV. U ma agenda para a saúde. 2 a ed. São Paulo: Hucitec; 1999
15. Berlinguer G. Ética da saúde. São Paulo: Hucitec; 1996.

16. Soares JCRS, Camargo Junior KR. A autonomia do paciente no processo terapêutico com valor para a saúde. Interface - Comunicação, Saúde, Educação 2007: 11(21):65-78.

17. Brasil. Conselho Nacional de Saúde. Lei Orgânica da Saúde, no 8.080, de 19 de setembro de 1990 . Dispõe sobre as condições para a promoção e recuperação da saúde, a organização e o funcionamento dos serviços correspondentes e dá outras providências. Diário O ficial da União 1990; 20 set. [acessado 2004 ago 23]. Disponível em: http://www. senado.gov.br

18. Pinheiro R. As práticas do cotidiano na relação oferta e demanda dos serviços de saúde: um campo de estudo e construção da integralidade. In: Pinheiro $R, M$ attos RA, organizadores. Os sentidos da integralidade na atenção e no cuidado à saúde. Rio de Janeiro: IM S-U erj/Abrasco; 2001. p. 65-112.

19. M attos RA. Os sentidos da integralidade: algumas reflexões acerca de valores que merecem ser defendidos. In: Pinheiro R, M attos RA, organizadores. Os sentidos da integralidade na atenção e no cuidado à saúde. Rio de Janeiro: IM S-U erj/Abrasco; 2001. p. 39-64.

20. Ayres JRCM. Subjetividade, intersubjetividade e práticas de saúde. Cien Saude Colet 2001; 6(1):63-72.

21. Ayres JRCM. Análise do discurso oficial sobre a humanização da assistência hospitalar. Cien Saude Colet 2000; 6(1):63-72.

22. Kottow M. Bioética da proteção: considerações sobre o contexto latino americano. In: Schramm FR, Rego S, Braz M, Palácios M, organizadores. Bioética: riscos e proteção. Rio de Janeiro: UFRJ/Editora Fiocruz; 2005. p. 29-44.

Artigo apresentado em 11/12/2007

Aprovado em 26/01/2009

Versão final apresentada em 26/02/2009 